\title{
Influência da tomada de decisão no manejo produtivo de ovinos do município de São Sepé - RS
}

Influence of decision-making upon the productive manner of ovine in São Sepé - RS

\author{
Marciele Barbieri, Viviane Schons de Ávila, Ana Paula Burin, Andrea Cristina Dörr
}

Universidade Federal de Santa Maria - UFSM

\section{Resumo}

Para que uma produção de ovinos seja eficiente, devem-se aplicar os critérios técnicos básicos de produção, ou seja, identificar o tipo de produto a ser produzido, definir os objetivos, a raça a ser criado, número de animais em função do tamanho da área, e as práticas de manejo adequadas ao sistema de produção escolhido pelo produtor. O objetivo trabalho deste é analisar quais são os fatores que os produtores de ovinos do município de São Sepé - RS utilizam como tomada de decisão na ovinocultura. Inicialmente, realizou-se uma revisão bibliográfica, de forma a caracterizar os agentes e processos envolvidos. Posteriormente, foram analisados dados estatísticos da produção de ovinos da cidade de São Sepé - RS. Com essas informações, elaboraram-se formulários semiestruturados que foram aplicados in locu a uma amostra de oito agentes participantes da cadeia ovina nas unidades produtivas, nos dias 31 de Janeiro e 01 de Fevereiro de 2012. Os resultados mostram que a gestão e controle contábil da propriedade são fundamentais para auxiliar na tomada de decisões, tanto de organizações agroindustriais quanto de propriedades rurais, envolvendo os processos produtivos e seu controle. Conclui-se, que a tomada de decisão no momento da aplicação de algum tipo de manejo exige conhecimento e poder de decisão.

Palavras chaves: Ovinocultura, tomada de decisão, manejo produtivo.

\begin{abstract}
For a sheep production to be effective, they must apply the basic technical criteria of production, i.e. identify the type of product being produced, define the goals, the race to be created, number of animals depending on the size of the area, and the management practices appropriate to the production system chosen by the producer. The objective of this study is to analyze what are the factors that the sheep producers of São Sepé-RS use as decision-making in the sheep industry. Initially, a literature review was performed in order to characterize the agents and processes involved. Subsequently, we analyzed statistical data of sheep production in the city of São Sepé-RS. With this information, semi-structured forms have been applied in locu a sample of eight participating agents in productive chain, on 31 January and February 1, 2012. The results show that the management and accounting control of property are fundamental to assist in decision-making, both of agro-industrial organisations and rural properties, involving the production processes and their control. It is therefore concluded that the decision at the time of application of some kind of management requires knowledge and decision power.
\end{abstract}

Key words: Sheep, decision-making, productive management. 


\section{INTRODUÇÃO}

A criação de ovinos está presente em diversos países, devido a diversidade de raças, que se desenvolveram nos diferentes climas e relevos existentes. Essa atividade pode ter finalidade econômica, como também pode ser praticada apenas para a subsistência. Para que uma produção de ovinos seja eficiente, devem-se aplicar os critérios técnicos básicos de produção, ou seja, identificar o tipo de produto a ser produzido, definir os objetivos, a raça a ser criada, número de animais em função do tamanho da área, assim como as práticas de manejo adequadas ao sistema de produção escolhido pelo produtor. Também é necessário avaliar as características de clima e mercado de cada região (VAZ, 2008).

Com relação à produção, o Brasil tem participação significativa na ovinocultura em nível mundial. De acordo com dados da FAO (2010), o Brasil apresenta uma produção de 116.750 toneladas de carne ovina, e uma produção de peles frescas de 15.200 toneladas, não apresentando participação significativa na produção de lã, estando inserida no agronegócio que, atualmente, consiste num ambiente de grande competitividade e mudanças constantes. Dessa forma, o produtor rural encontra-se em uma posição que exige iniciativas, sejam elas em investimento de novos produtos, novas tecnologias, ou até mesmo novos processos produtivos. No caso da ovinocultura, a falta de informações para os produtores sobre a projeção futura de oferta e demanda torna-se um fator de risco para o investimento. Para a tomada de decisão, o produtor necessita de muitas informações, as quais precisam ser analisadas, porém, no meio rural, a limitação estrutural e organizacional dificulta o acesso a dados consistentes e reais. Por isso, a tomada de decisão no meio rural é muito mais baseada na criatividade, intuição e experiência do que em métodos com suporte científico (CHAVES, et al 2010).

O rebanho de ovinos no Brasil, segundo dados do IBGE (2010), chegou a 17.380.581 cabeças, sendo que $56,7 \%$ deste rebanho concentra-se na Região Nordeste do país, onde estão nove dos 20 municípios com maiores efetivos. Os demais estão localizados no Rio Grande do Sul, responsável por 3.979.258 cabeças ovinas e Santa Catarina e Paraná com $28,1 \%$ do rebanho nacional. A criação na Região Nordeste é destinada ao abate, produção de leite e exploração da pele, com predomínio de raças deslanadas. A Região Sul, por sua vez, possui o papel de maior produtora nacional de lã, representando $98,5 \%$ da produção total. No mundo, existem de 800 a 1000 raças ovinas, criadas para propósito de carne, lã, leite, peles, e ainda com dupla ou tripla aptidão. Embora a região Sul fique em segundo lugar, no que se refere à região brasileira detentora do maior rebanho de ovinos, é no Rio Grande do Sul que se concentra a maior parte do rebanho brasileiro de ovinos. Além de apresentar condições climáticas favoráveis, as áreas de campo para criação dos ovinos apresentam boa composição botânica. O estado engloba um rebanho de 3.979 .258 ovinos, o que representa $23 \%$ do efetivo nacional. É também no Rio Grande do Sul que estão as cidades com maiores rebanhos do país, como por exemplo, Santana do Livramento e Alegrete, com 403.340 e 256.712 cabeças, respectivamente. O município de São Sepé, que faz divisa com esta região apesar de estar incluso na região central, também possui um alto efetivo, com um rebanho de 32.150 ovinos (IBGE, 2010), e neste município a atividade familiar ${ }^{1}$ se sobressai no setor de ovinocultura, pois a administração da propriedade e o controle da criação são feitos, basicamente, por membros da família. Os rebanhos são dispersos em áreas pequenas e médias, variando de 14 a 200 hectares e não há contabilização rígida de ganhos.

Nesse contexto insere-se o objetivo deste trabalho, que consiste em analisar os fatores utilizados pelos produtores de ovinos pertencentes à região Central do Rio Grande do Sul, especificamente do município de São Sepé, como lógica para tomada de decisão na atividade de ovinocultura, isto é, qual o fator determinante das decisões do manejo produtivo e qual sua importância, a fim de melhorar a produtividade.

\section{METODOLOGIA}

Realizou-se uma revisão bibliográfica a fim de caracterizar os agentes e processos envolvidos. Em seguida, foram analisados dados estatísticos da produção de ovinos no município de São Sepé -RS. A partir destas informações foram elaborados formulários semiestruturados, que foram aplicados in locu a uma amostra de oito agentes participantes da cadeia ovina nas unidades produtivas nos dias 31 de Janeiro e 01 de Fevereiro de 2012.

De modo geral, o estudo de caso é aplicável quando se deseja obter generalizações analíticas e

\footnotetext{
Agricultura familiar refere-se a "todo aquele (a) agricultor (a) que tem na agricultura sua principal fonte de renda $(+80 \%)$ e que a base da força de trabalho utilizada no estabelecimento seja desenvolvida por membros da família. (BARROS, 2012)
} 
não estatísticas, que possam contribuir para certo referencial teórico. A pesquisa, por meio de estudos de caso, tem sido enquadrada no grupo de métodos denominados qualitativos, que se caracteriza por um maior foco na compreensão dos fatos do que propriamente na sua mensuração. Dessa forma, contrasta-se com os métodos quantitativos, que se preocupam mais em mensurar fenômenos e são aplicados a amostras mais extensas (LAZZARINI, 1997).

Para este trabalho, optou-se pela análise de estudos de caso múltiplos, cuja vantagem reside no fato de proporcionarem evidências inseridas em diferentes contextos, o que acaba tornando a pesquisa como um todo mais robusto (YIN, 1989). Após a aplicação dos formulários, os dados de cada um dos oito produtores foram analisados com base nos resultados, elaborou-se uma análise de cenário da cadeia produtiva.

\section{RESULTADOS E DISCUSSÃO}

\section{I Perfil da produção do município de São Sepé}

Na visita ao município de São Sepé, nos dias 31 de janeiro e 01 de fevereiro de 2012, foram entrevistados oito produtores rurais, os quais possuíam a ovinocultura como importante fonte de renda. A partir desta análise, observou-se que a carne ovina aparece como o produto de maior rentabilidade aos produtores, seguida pela produção de lã e peles. Na Tabela 1, pode-se observar a área total das propriedades visitadas, assim como a proporção assumida pela ovinocultura nas mesmas. No município de São Sepé, onde o módulo fiscal possui o valor de 35 hectares, $37,5 \%$ das propriedades entrevistadas são classificados como minifúndios, $12,5 \%$ são consideradas pequenas pro- priedades, e a maior parte (50\%), por sua vez, são médias propriedades. Ao efetuar uma análise de correlação entre as variáveis área total e percentual destinado a criação de ovinos, observou-se um índice de -0,45. Este resultado indica que quanto maior a área da propriedade, menor será o valor relativo destinado à produção de ovinos, o que também demonstra que a ovinocultura assume maiores proporções em pequenas propriedades.

Tabela 1 - Área total da propriedade e porcentagem desta destinada a ovinocultura.

\begin{tabular}{c|c|c}
\hline Propriedade & Área Total (ha) & $\begin{array}{c}\% \text { destinada à criação } \\
\text { de ovinos }\end{array}$ \\
\hline 1 & 300 & 66,67 \\
\hline 2 & 380 & 39,47 \\
\hline 3 & 175 & 17,14 \\
\hline 4 & 15 & 100,00 \\
\hline 5 & 44 & 27,27 \\
\hline 6 & 30 & 100,00 \\
\hline 7 & 148 & 100,00 \\
\hline 8 & 14 & 100,00 \\
\hline
\end{tabular}

Fonte: Dados da pesquisa

Na Figura 1, observa-se o número total de cabeças de animais existentes na propriedade, comparado ao número de cabeças de ovinos. Os dados revelam que em $62,5 \%$ das propriedades, o número de ovinos é superior ao das outras espécies. Já em $25 \%$ das propriedades, o número de ovinos representa menos da metade do número total de animais. E por fim, em 12,5\% das propriedades, o número de outras espécies é maior do que o número de cabeças ovinas.

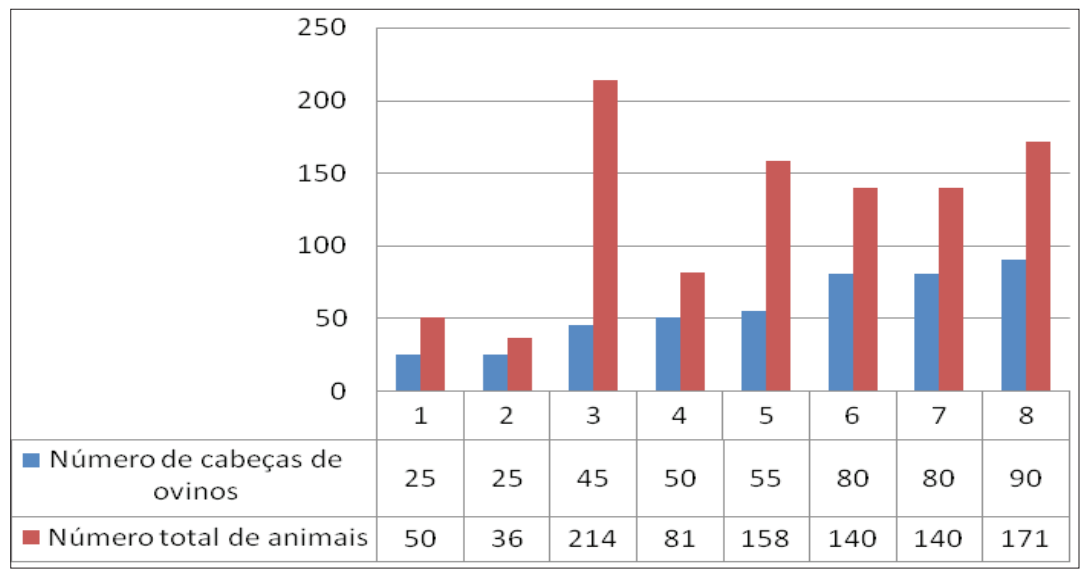

Figura 1 - Quantidade total de animais e de cabeças ovinas existentes na propriedade. Fonte: Dados da pesquisa 
A rentabilidade da atividade, para esses produtores, é difícil de ser mensurada com exatidão, pois a maioria deles, não costuma fazer registros de todas as entradas e saídas. No entanto, através das informações obtidas nas propriedades visitadas, a renda bruta média com ovinos vivos varia entre $\mathrm{R} \$ 2.700,00$ e $\mathrm{R} \$ 7.800,00$ por ano. A renda média bruta com a lã, por sua vez, varia entre R\$ 360,00 e R \$ 6.750,00 por ano. Grande parte deles apresenta um longo tempo de experiência com a criação de ovinos, visto que a atividade é de tradição familiar. Apesar disso, não são todos os filhos que dão continuidade a atividade no campo. Essa é uma das principais características existentes na agropecuária atual, principalmente no caso de pequenos produtores, em que os filhos migram para a cidade em busca de outras atividades. Apenas um produtor entrevistado possui mão-de-obra fixa contratada, enquanto que quatro deles contratam empregados temporários, demonstrando que a maioria utiliza mão-de-obra familiar (do casal e, às vezes, de um dos filhos). A contratação de trabalhadores para o campo é considerada difícil para $50 \%$ dos produtores.

\subsection{Gerenciamento da produção e a tomada de decisão}

Apenas três produtores fazem o registro de entradas e saídas desde a compra dos animais até a comercialização, juntamente com o controle financeiro da propriedade. Os demais apenas controlam os animais da propriedade, guardam as notas de compra e possuem o talão do produtor para ter uma noção das vendas feitas, e ainda, um dos entrevistados não faz qualquer tipo de controle contábil. Apesar da maioria não ter o hábito de registrar entradas e saídas de caixa, $100 \%$ dos entrevistados afirmaram que fazer controle das operações realizadas é importante para o melhor gerenciamento da atividade.

Portanto, a partir dos dados que os produtores possuem, sejam eles em cadernos ou em tabelas no computador, torna-se fundamental para retirarem as informações que julgam necessárias e satisfatórias, para uma as tomadas de decisões. Cita-se como exemplo, a compra de mais animais para a propriedade, a compra de medicamentos para os ovinos, a compra de sêmen para inseminação artificial. Desse modo, a maioria dos produtores não sabe exatamente qual a rentabilidade obtida com a criação de ovinos.

\section{CONCLUSÕES}

A falta de gerenciamento e controle contábil das propriedades é um fator que prejudica as tomadas de decisões na ovinocultura, seja ela relativa à compra de animais ou de algum processo de manejo. Isso demonstra a importância de adequar um sistema simples para gerenciamento da atividade, de modo que o próprio produtor possa analisar se é viável a sua permanência nesse ramo da pecuária, e para que consiga tomar decisões de investimento e de vendas, com mais certeza dos resultados.

O tradicionalismo dos produtores e a falta de conhecimento quanto à importância do gerenciamento da propriedade também é um fator que interfere negativamente no sucesso da propriedade. Caberia aos filhos jovens darem continuidade ao trabalho no campo, com ideias inovadoras e maior noção da importância do gerenciamento, porém, a maioria deles migra para as cidades em busca de estudo e outras profissões. Evidencia-se a importância de aprimoramento na atividade rural, em busca de inovações que atraiam os jovens para dar continuidade aos trabalhos no campo, agregando valor aos produtos e desenvolvendo o setor.

Dessa forma, percebe-se que o controle contábil e gerenciamento da propriedade são ferramentas muito importantes para as tomadas de decisões dentro da propriedade, tendo em vista que a ovinocultura ocupa mais da metade da área total da maioria das propriedades entrevistadas, assim como o número de ovinos também é superior ao número total de animais na maioria delas.

\section{REFERÊNCIAS}

CHAVES, R. Q. de. Tomada de decisão e empreendedorismo rural: um caso da exploração comercial de ovinos de leite. Revista Brasileira de Gestão e Desenvolvimento Regional, v. 6, n. 3, p. 3-21, setdez/2010, Taubaté, SP, Brasil.

DRIVER, M. J.; BROUSSEAU, K. R.; HUNSAKER, P. L. HOONEY, G. The dynamic decision-maker: five decision styles for executive and business success. New York: Harper and Row, 1990. 264p

DUTRA, A. S.; MACHADO, J. A. D.; RATHMANN, R. O Processo decisório de implantação de estrutura de armazenagem de soja ao nível de propriedade rural na região de Santo Ângelo/RS. ZLVI SOBER - Rio Branco - AC, Jul-2008. 
DUTRA, A. S.; MACHADO, J. A. D.;

RATHMANN, R. Alianças estratégicas e visão baseada em recursos: Um enfoque sistêmico do processo de tomada de decisão nas propriedades rurais. ZLVI SOBER - Rio Branco - AC, Jul-2008.

FAOSTAT. FAO Statistics Division, 2010. Disponível em: < http://faostat.fao.org/site/573/DesktopDefault.aspx?PageID=573\#ancor $>$. Acesso em Fevereiro de 2012.

LAZZARINI, S. G. Estudo de caso para fins de pesquisa: aplicabilidade e aplicações do método. In: FARINA, M. M. Q. (Coord.). Estudos de caso em agribusiness. São Paulo: Pioneira, 1997. p. 9-23.

LEIBENSTEIN, H. Beyond economic man. Cambridge: Harvard University Press, 1976.

OLIVEIRA, L. M.; MACHADO, J. A. D.; SHNORREMBERGER, A. A informação e o processo decisório do produtor rural. LVI SOBER - Londrina-PR, Jul-2007.

RATHMANN, R. et al. Uma proposta de estrutura analítica sistêmica para o estudo da decisão nos agronegócios. XLV SOBER - Londrina - PR, Jul2007.

SIMON, H. A. Administrative behavior. New York: MacMillam, 1945.

SIMON, H. A. Models of discovery. Dordrecht: Holland, D. Reidel Publishing Company, 1977.

SIMON, H. A. Comportamento administrativo: estudo dos processos decisórios nas organizações administrativas. Rio de Janeiro: Fundação Getúlio Vargas, 1970.

VAZ, C.M.S.L.; KALIL, R.G.; VILLARROEL, A.S. Sistema de Criação de Ovinos nos Ambientes Ecológicos do Sul do Rio Grande Do Sul. Embrapa Pecuária Sul Sistema de Produção. Versão Eletrônica. 2008. Disponível em: <http://sistemasdeproducao.cnptia.embrapa.br/FontesHTML/Ovinos/ CriacaoOvinosAmbientesEcologicosSulRioGrandeSul/racas.htm\#topo>. Acesso em: 15 jan. 2012.

YIN, Robert K. Estudo de Caso, planejamento e métodos. 2.ed. São Paulo: Bookman, 2001. 